\title{
3 Chemical origin of tectonic tremor
}

4

Tectonic tremor may ultimately be caused by in-situ fluid overpressure generated by chemical reactions between a subducting slab and the mantle, according to field and microstructural observations of a shear zone.

Kohtaro Ujiie

Episodic, simultaneous occurrences of long-period seismicity and fault slip lasting days or weeks ${ }^{1}$ are common in subduction zones ${ }^{2,3}$. Where young and warm slabs subduct, these episodes of tectonic tremor and slow slip are typically observed along the plate boundary near the corner of the mantle wedge (Fig. 1a). The location of episodic tremor and slip is thought to represent the transition between the unstable locked seismogenic zone and the stable slipping zone ${ }^{1}$. Therefore, the geological and rheological conditions of episodic tremor and slip are important in defining the limit of the seismogenic zone, yet they remain poorly understood. Writing in Nature Geoscience, Tarling et al. ${ }^{4}$ present geological observations of a shear zone with rocks comprised of serpentine minerals, and propose that chemical reactions there generate fluid overpressure that, in turn, enables tremor-inducing brittle faulting where viscous shear is otherwise predominant.

Episodic tremor and slip (ETS) was first discovered at the downdip side of the seismogenic megathrust in warm-slab environments such as Cascadia and Nankai ${ }^{2,3}$. Tectonic tremor and slow slip events have since been reported in other tectonic settings, including the updip side of the seismogenic zone in both warm- and cold- slab subduction environments and at transform faults ${ }^{5-7}$. Geophysical observations consistently show that the ETS zone near the mantle wedge corner has fluid overpressures comparable to the confining pressure, and that such fluid overpressures lead to frictional rather than viscous behaviour ${ }^{8}$. Fluid overpressures are commonly thought to result from dehydration of hydrous minerals in the subducted rocks (Fig. 1b). The plate boundary and other shear zones exhumed from depths at which ETS occurs provide an opportunity to examine the geological and rheological conditions of ETS at 
34 finer spatial resolution than from geophysical observations. Studies of these shear zones

35 have suggested that ETS is controlled by coupled brittle-viscous deformation of rigid

36 lenses within a viscous matrix ${ }^{9,10}$, and that ETS is recorded by crack-seal shear veins

37 formed contemporaneous with viscous shear zones ${ }^{11,12}$.

38 Tarling et al. present field and microstructural observations of the 39 400-m-thick Livingstone Fault shear zone in New Zealand, which comprises diverse 40 blocks in a serpentine-bearing matrix. The observations indicate that metasomatism, i.e. 41 rock-altering reactions, driven by gradients in chemical potential between 42 compositionally disparate rocks, released fluid that caused overpressure in the shear 43 zone (Fig. 1c). The resulting mix of brittle and viscous deformation suggests that in-situ 44 fluid release by metasomatism may be an important factor in controlling brittle faulting 45 and tremor in viscous shear zones, in addition to mineral dehydration from the 46 subducting slab.

47 Tarling et al. also compile data on pressure-temperature conditions for 48 metasomatism in serpentine-bearing assemblages. This occurs at temperatures of about 49100 to $550{ }^{\circ} \mathrm{C}$ and at pressures of around 100 to $1000 \mathrm{MPa}$, a range that encompasses 50 the conditions of ETS near the mantle wedge corner. Although Tarling et al. study a 51 transform fault, paleo-subduction faults observed in exhumed accretionary complexes 52 are often characterized by similar mélange zones, comprising sheared rocks of diverse 53 size and lithology, susceptible to metasomatism. In light of Tarling et al., further 54 geological investigation of chemical reactions in mélange shear zones deformed under 55 various temperature and pressure conditions is required. This is key to understanding 56 whether the generation of tremor by in-situ fluid overpressure is restricted to the vicinity 57 of the mantle wedge corner or if it is widespread in subduction zones.

58 The time intervals between tremor-generating fluid overpressure events and 59 the time scales for fluid-rock interactions associated with metasomatism remain poorly 60 constrained. Recent geological studies of plate boundary shear zones have revealed 61 pulse-like fluid flow events over 1 to 4 months $^{13}$ and precipitation times of less than a 62 few years between crack-seal events ${ }^{12}$, which are comparable to the time scale of slow 63 earthquakes. Estimation of the time scale of metasomatism will provide critical 64 information to assess whether repeated fluid pressure rise and fracturing are associated 65 with slow earthquakes.

$66 \quad$ Tarling et al. show that in-situ metasomatism-related fluid pressurization and 
67 the resultant brittle faulting, indicated by mineralized veins and reaction zones, is a

68 plausible geological explanation for tectonic tremor in subduction zones.

69

70 Kohtaro Ujiie

71 Doctoral Program in Earth Evolution Sciences, Graduate School of Life and 72 Environmental Sciences, University of Tsukuba, Japan

73 e-mail: kujiie@geol.tsukuba.ac.jp

74

75

\section{References}

76 1. Peng, Z. \& Gomberg, J. Nat. Geosci. 3, 599-607 (2010).

77 2. Rogers, G. \& Dragert, H. Science 300, 1942-1943 (2003).

78 3. Obara, K., Hirose, H., Yamamizu, F. \& Kasahara, K. Geophys. Res. Lett. 31, L23602 79 (2004).

80 4. Tarling, M. S., Smith, S. A. F. \& Scott, J. M. Nat. Geosci. 81 https://doi.org/10.1038/s41561-019-0470-z (2019).

82 5. Araki, E. et al. Science 356, 1157-1160 (2017).

83 6. Nishikawa, T. et al. Science 365, 803-813 (2019).

84 7. Shelly, D. R. Nature 463, 648-652 (2010).

85 8. Gao, X. \& Wang, K. Nature 543, 416-419 (2017).

86 9. Hayman, N. W. \& Lavier, L. L. Geology 42, 195-198 (2014).

87 10. Behr, W. M., Kotowski, A. J. \& Ashley, K. T. Geology 46, 475-478 (2018).

88 11. Fagereng, Å., Remitti, F. \& Sibson, R. H. Tectonophysics 510, 381-386 (2011).

89 12. Ujiie, K. et al. Geophys, Res. Lett. 45, 5371-5379 (2018).

90 13. Taetz, S., John, T., Bröcker, M., Spandler, C. \& Stracke, A. Earth Planet. Sci. Lett. $91 \quad 482,33-43(2018)$. 

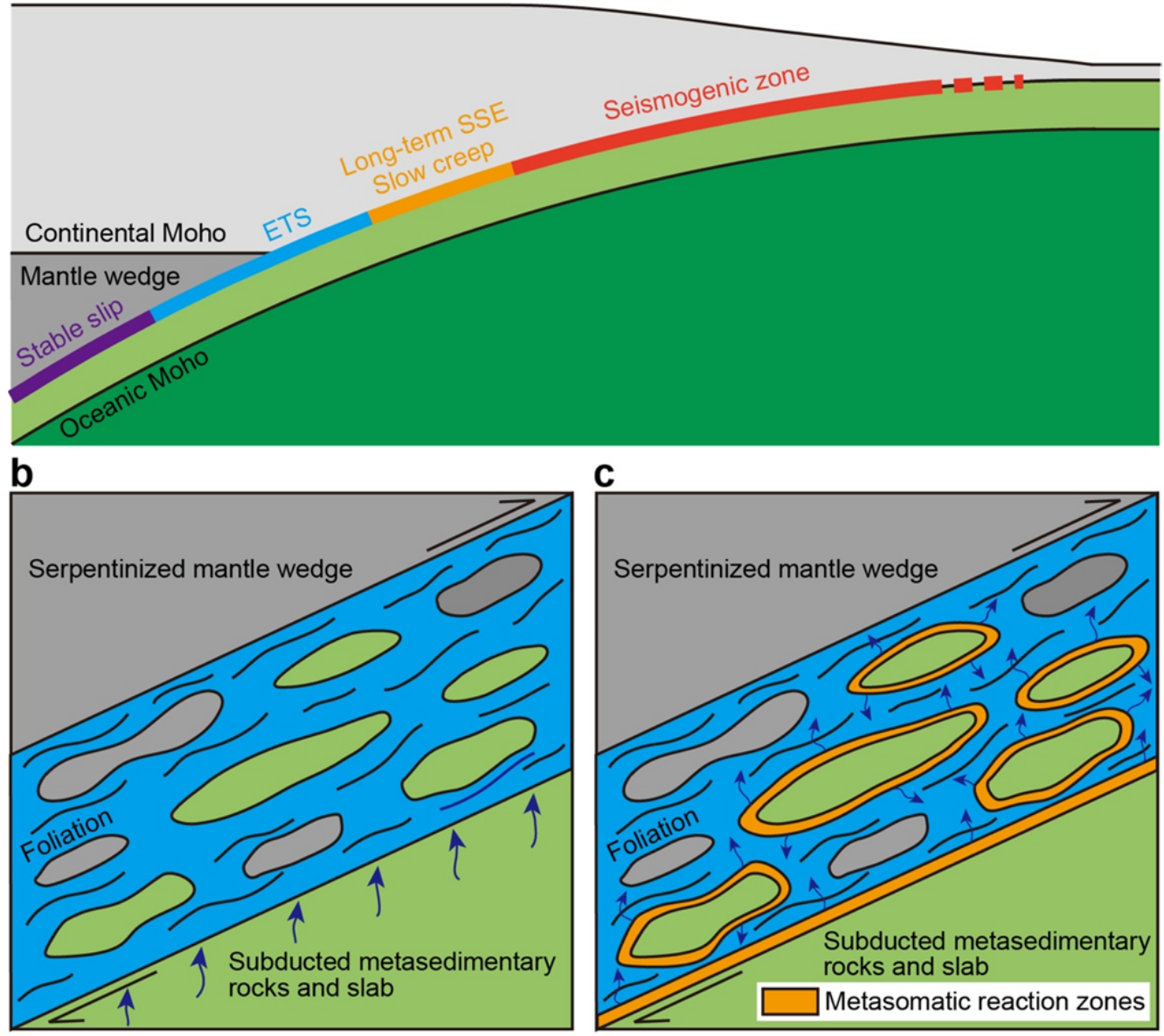

Fig. 1. Schematic illustration of the source of tectonic tremor. a) Schematic cross

96 section of a subduction zone showing how the slip mode changes down the plate 97 interface, from earthquakes to slow slip events (SSEs), then episodic tremor and slip 98 (ETS), and then continuous slip. b) Fluid overpressure is produced by dehydration of 99 hydrous minerals in subducted rocks, and migrates into the plate boundary shear zone to 100 generate tremor under low effective stress conditions. c) Tarling et al. ${ }^{4}$, however, 101 propose that in-situ fluid overpressures result from metasomatic reactions in the shear 102 zone, and lead to brittle shear failure responsible for tremor. The blue arrows in $\mathbf{b}$ and $\mathbf{c}$ 103 indicate fluid release. 